\title{
ARQUIVOS DA MEMÓRIA: ABY WARBURG, A HISTÓRIA DA ARTE E A ARTE CONTEMPORÂNEA
}

\author{
Claudia Valladão de Mattos ${ }^{1}$
}

Nas últimas décadas a obra de Aby Warburg tem sido posta no centro de uma revisão das formas tradicionais da história da arte. Esta centralidade do autor para nossa disciplina deve-se, como afirma Michael Diers, muito mais às "suas demandas específicas e ao seu programa de trabalho, do que aos resultados reais de suas pesquisas." 2

Nascido em 1866, como filho primogênito de um rico banqueiro judeu alemão de Hamburgo, Warburg é agora principalmente lembrado como o idealizador e fundador da importante Biblioteca Warburg, hoje sediada em Londres e como mentor da assim chamada "Escola de Warburg", vinculada às atividades daquela biblioteca, que inclui importantes nomes da historia da arte, como Erwin Panofsky, Fritz Saxl, Edgard Wind, Gombrich, entre outros. A relevância desta "Escola" no contexto da disciplina História da Arte foi, no entanto, em parte a responsável pelo desconhecimento que se instalou, durante muitas décadas, em torno das pesquisas e verdadeiros objetivos de Aby Warburg, após a sua morte em 1929. Com o passar do tempo, o nome de Warburg foi sendo identificado com aquele de seus sucessores, e em especial com os métodos da iconologia de Panofsky, que, no entanto, eram bastante diferentes dos métodos por ele defendidos. Como diz Diers, enquanto Panofsky e seus sucessores preocupavam-se cada vez mais, numa performance erudita, com a decifração do significado do conteúdo representado em uma determinada imagem, eles paulatinamente também se afastavam das preocupações centrais de Aby Warburg, que, antes de tudo, voltava-se para questões de psicologia da imagem, isto é, para investigações a respeito das formas assumidas pelas imagens e das razoões que determinam suas transformações no tempo. Neste processo, a iconologia, enquanto ciência da imagem, pode ser absorvida com facilidade no espectro maior das metodologias tradicionais da história da arte, perdendo o caráter eminentemente crítico e, por assim dizer, subversivo inerente às concepções de Warburg.

Vejamos então rapidamente quais eram os pilares conceituais do programa original de Aby Warburg. Desde muito cedo, já em seus estudos sobre Botticelli para o doutorado em História da Arte defendido na universidade de Bonn, Warburg mostrou-se interessado pela questão da sobrevivência de formas de um tempo passado em outro. ${ }^{3}$ No caso do trabalho sobre Botticelli -- e de muitos outros que empreendeu ao longo de sua carreira -este interesse voltou-se para a investigação da sobrevivência de formas clássicas no contexto da cultura do Renascimento italiano. Enquanto estudava os quadros de Botticelli em Florença, Warburg observou uma grande preocupação do artista em reproduzir os movimentos de vestes e cabelos de algumas figuras femininas, constatando que, para tal, ele havia tomado obras antigas como modelo, principalmente figuras de Ninfas presentes em sarcófagos greco-romanos. O que intrigou Warburg, no entanto, foi a ênfase excessiva dada aos movimentos e seu caráter freqüentemente anti-naturalista, que contradizia a idéia largamente aceita por acadêmicos do período de que a cultura do renascimento poderia ser

\footnotetext{
1 Prof $^{a}$ Dra $^{a}$., Instituto de Artes, Unicamp.

2 Michael Dirs; Thomas Girst; Dorothea von Moltke, "Warburg and the Warbugian Tradition of Cultural History", in: New German Critique, n. 65 (Spring-Summer, 1995), p. 59-73.

3 Aby Warburg, "Sandro Botticelli's Birth of Venus and Spring. An Examination of Concepts of Antiquity in the Italian Early Renaissance", in: The Renewal of Pagan Antiquity, Los Angeles: Getty Research Institue, 1999, p. 89-156.
} 
compreendida como uma marcha segura em direção a um crescente naturalismo (afirmação que também aparecia em escritos da época, como os tratados de Alberti a Vasari). Essas observações levaram Warburg a pensar em uma motivação psicológica para a reutilização de determinadas formas antigas no contexto da cultura florentina do quattrocento. Lemos, por exemplo, em uma das notas preparatórias de Warburg para sua tese de doutorado: "Uma vez que é certo que, desde o começo do quattrocento a demanda predominante com relação à representação da figura humana era o da fidelidade à natureza, temos o direito de considerar qualquer desvio arbitrário com relação a esta fidelidade - seja na repetição freqüente de motivos individuais, ou na distorção não-natural de um objeto - como a manifestação de desejos insatisfeitos causados pela visão de mundo do periodo e dirigidos para um desfrutamento da vida. Devemos descobrir:

1) Esses traços em qualquer período dado, de forma a estabelecer sua fisionomia histórica. É necessário investigar se houve qualquer imitação de modelos anteriores.

2) A produção da arte como parte da vida de uma época"

Ainda que indiretamente, já encontramos aqui formulado o conceito de Pathosformel, que Warburg passaria a usar a partir de 1905 para explicar sua concepção de transmissão de uma memória coletiva através de imagens. ${ }^{5}$ Esse modelo expandiu-se nos anos seguintes, tornando-se cada vez mais universal, até encontrar uma formulação definitiva no último projeto inacabado de Warburg, seu Bilderatlas Mnemosyne (Mapa de imagens da memória).

O projeto Mnemosyne consistia em uma síntese de seu pensamento sobre a função psico-social das imagens, organizada visualmente em 63 pranchas contendo fotografias que ilustravam a história da permanência de determinados valores expressivos, dotados de uma "força formadora de estilo" (stilbildende Marcht), que seriam transmitidos em forma de imagens, como um patrimônio sujeito a leis complexas de transformação e recepção (Fig. 1). De acordo com a concepção de Warburg, as imagens seriam formadas por motivações psíquicas relacionadas a uma determinada época e carregadas para dentro de outras culturas, onde seriam remobilizadas em seus conteúdos psíquicos e reorganizadas em função do novo contexto.

Como observou Didi-Hüberman ${ }^{6}$ em seu livro sobre o autor, Warburg desenvolveu nesse projeto uma teoria da história calcada numa temporalidade não linear, onde as imagens, portadoras de uma memória coletiva, romperiam com o continuum da historia, traçando pontes entre o passado e o presente. Funcionando como "sintomas", no sentido freudiano, as imagens sobreviveriam e se deslocariam temporalmente e geograficamente, criando fenômenos diacrônicos complexos. Warburg conceberia as imagens como símbolos condensadores de uma memória coletiva, que circulariam através do tempo, reativando-se e modificando-se ao inserirem-se em momentos históricos específicos. Para explicar essa sobrevivência da imagem passada em outras culturas, Warburg desenvolveu o conceito de Nachleben, ou pós-vida, das imagens. Fritz Saxl, colaborador de Warburg aproximou tal conceito da idéia de arquétipos de Jung. Didi-Hüberman, no entanto, rejeitou tal aproximação, com argumentos semelhantes aos levantados pelo filósofo Giorgio Agamben de que "As imagens para Warburg [à diferença dos arquétipos de Jung] são realidades históricas, inseridas num processo de transformação das culturas, e não entidades a-históricas."

\footnotetext{
${ }^{4}$ Ernst Gombrich, Aby Warburg. An Intellectual Biography, Chicago: Chicago University Press, 1986, p. 47.

5 Warburg mencionaria o conceito pela primeira vez em seu texto sobre Albert Dürer, em 1905.

${ }^{6}$ Georges Didi-Huberman, L'Image Survivante. Histoire de L'Art et Teps de Fantômes selon Aby Warburg, Paris: Les 'Editions de Minuit, 2002.
} 
O Atlas Mnemosyne, como dissemos, tinha por objetivo esclarecer visualmente o processo complexo de circulação das imagens coletivas dentro da história da civilização ocidental, identificado por Warburg. Certamente este mapa era incompleto para seu autor e necessitaria ser ampliado para abarcar as relações entre as diversas culturas de toda a humanidade, (basta lembrar as comparações estabelecidas por Warburg entre a cultura primitiva dos índios Hopi da América do Norte e a cultura florentina da época dos Médici'). Na montagem, deixada incompleta por ocasião de sua morte em 1929, cada símbolo registrado funciona como um arquivo da memória coletiva, posto numa relação com todos os outros, formando grandes constelações que cruzam conceitos espaciais e temporais na história.

A breve descrição dos métodos e do programa de Warburg permite vislumbrar as razões para o grande interesse que ele tem despertado em historiadores da arte determinados a proceder a uma revisão crítica dos instrumentos e métodos tradicionais da Historia da Arte. O modelo de Warburg resiste às visões da história e dos fenômenos de transmissão e imitação de modelos construídos tradicionalmente pela disciplina da História da Arte desde Winckelmann. A história da arte tradicional (ainda largamente praticada hoje em dia) sustenta uma noção linear de tempo expressa por uma supervalorização das etapas cronológicas observadas, tanto no contexto individual de criação artística, quanto no processo de transmissão de modelos artísticos dentro de uma cultura. Associada a isto, uma concepção de progresso persiste, calcada num inevitável Eurocentrismo. Também o mapa geográfico da historia da arte, a divisão das produções diversas por escolas nacionais, por exemplo, encontra em Warburg um momento de grande resistência. Como diz DidiHüberman, o modelo de Warburg mostra-se capaz de provocar uma desorientação da história, promovendo a crítica das concepções tradicionais de História da Arte.

O modelo de Warburg ainda apresenta outra vantagem, indispensável para pensarmos a arte de um ponto de vista contemporâneo. À diferença das concepções tradicionais da disciplina que procuravam estudar o fenômeno artístico como elemento autônomo (ou semi-independente) de outros círculos da cultura, Warburg concebia a imagem como um espaço de embricamento de valores psicológicos, políticos, sociais, religiosos, visão, aliás que ele emprestara de Jacob Burckhardt. Essa visão complexa do fenômeno artístico é essencial para compreendermos muitas das manifestações da arte contemporânea.

\section{Aby Warburg e o campo da Arte:}

O papel do historiador da arte como decifrador de imagens de uma memória coletiva implicava ainda uma revisão do papel tradicional do historiador da arte. Este é um dos pontos importantes do argumento que desenvolverei a seguir, que tratará da aproximação entre os campos da criação artística e o da história da arte vislumbrada nas concepções de Aby Warburg.

Analisando a obra de Warburg, Edgard Wind escreveria: "Warburg estava convencido que, em seu próprio trabalho, quando ele estava refletindo sobre as imagens que analisava, estava realizando uma função análoga àquela da memória pictórica quando, sob a urgência compulsiva de se expressar, a mente sintetiza espontaneamente imagens análogas ás das rememorações de formas pré-existentes. A palavra Mnemosyne, que Warburg inscreveu sobre a entrada de seu instituto de pesquisa, é para ser entendida nesse duplo sentido: como um lembrete para o estudioso de que ao interpretar uma obra do

${ }^{7}$ Aby Warburg, Schlangenritual. Ein Reisebericht, Berlin: Verlag Klaus Wagenbach, 1995. 
passado ele está agindo como guardião de um deposito de experiência humana, mas ao mesmo tempo como um lembrete de que esta experiência é ela mesma um objeto de pesquisa, que exige de nós que usemos material histórico para investigar como a 'memória social' funciona." ${ }^{8}$

Warburg considerava que seu trabalho de decifração das imagens dependia de sua posição histórica especifica e tinha consciência de estar atuando na cadeia de revitalização das imagens coletivas do passado, da mesma forma que o artista, ao criar sua obra.

Wolfgang Kemp foi o primeiro a tratar desse paralelismo entre os métodos de Warburg e as manifestações artísticas de seu tempo, ao mostrar afinidades entre o projeto Mnemosyne e as foto-montagens surrealistas, ou as obras de um artista como Kurt Schwitters. De acordo com o autor, a comparação servia principalmente para argumentar que as montagens dadaístas e surrealistas eram também construtoras de significado e não apenas arranjos aleatórios de formas.'

A partir desta aproximação, gostaria de considerar aqui brevemente a relevância do pensamento de Warburg para a produção de uma porção considerável da arte contemporânea: aquela que se propõe a investigar as estruturas da memória e o funcionamento dessas estruturas no contexto das sociedades atuais, isto é, que se interessam pelas questões do que poderíamos chamar política da memória. Em um artigo ainda inédito, apresentado na Unicamp em 2001, Siegrid Weigel descreveu da seguinte forma este campo artístico: "Com crescente nitidez, muitos empreendimentos artísticos não se entendem apenas como um trabalho com 'historia e lembrança'; [...] antes, eles também colocam as práticas materiais e simbólicas da própria memória no centro de seus trabalhos. Assim, a memória da arte, transformou-se na arte da memória." ${ }^{10}$

Em seu texto, Siegrid Weigel descreve obras de artistas recentes, como Jochen Gerz e Marina Abramovic, que tematizam a questão do arquivo, para em seguida mostrar as afinidades existentes entre esses trabalhos, que de acordo com ela, encenam "passagens entre os objetos e suas alfabetizações na memória cultural" e o programa desenvolvido por Warburg em seu Atlas Mnemosyne. Gostaria aqui de apontar para relações estabelecidas entre processos de alguns artistas e aqueles de Warburg num período um pouco anterior, mas que talvez já compartilhe muitas das questões abordadas pelas gerações recentes de artistas citados por Weigel. Meu argumento central é semelhante ao de Weigel e outros: as catástrofes do século XX funcionaram em larga medida como mobilizadoras dessa nova "arte da memória". O intenso e perverso uso das imagens no contexto da Alemanha nazista e dos regimes ditatoriais experimentados ao longo do século, e principalmente os debates a respeito da preservação da memória dessas catástrofes, foram em grande parte responsáveis pelo profundo interesse que podemos identificar entre muitos artistas com relação aos processos da memória, às políticas da memória e ao funcionamento das imagens nesse contexto. São essas as mesmas questões que, postas por alguns historiadores da arte, trouxeram as proposições de Aby Warburg para o centro da cena de uma História da Arte de visão crítica no mesmo período. De certa forma, as reflexões a respeito da "arte da memória" (para usar o termo consagrado), ou mais especificamente, o interesse por questões referentes à memória coletiva, podem ser identificadas já nas obras de alguns

\footnotetext{
${ }^{8}$ Diers et allii, op.cit., p. 70.

${ }^{9}$ Wolfgang Kemp, "Benjamin und Aby Warburg”, in: Kritische Berichte, Jg. 3, 1975, Heft 1, p.5 ss.

10 Siegrid Weigel, "A Arte da Memória - Memória da Arte. Entre o arquivo e o Atlas de imagens, entre a alfabetização e o vestígio", in: Márcio Seligmann-Silva (org.), Memória da Arte - Arte da Memória, São Paulo: Ateliê, no prelo.
} 
artistas nos anos 60 e 70. Tratarei aqui, para concluir, de dois exemplos, um europeu e um brasileiro, que a meu ver confirmam o paralelo que estamos traçando com a obra de Warburg: Ron B.Kitaj e Wesley Duke Lee.

A relação de Ron Kitaj com o universo intelectual de Aby Warburg é sem dúvida mais evidente que a de Wesley e comprova-se diretamente através de uma obra que o artista realizou em 1962, sob o título "Warburg como Mênade" (Fig. 2). Segundo Martin Roman Deppner ${ }^{11}$, o quadro seria uma homenagem do artista a Warburg, cujo pensamento Kitaj estudou em profundidade durante seus anos de formação no "Royal College of Art" em Londres. Nesse período, Kitaj freqüentara a Biblioteca Warburg, interessando-se especialmente pelo projeto Mnemosyne. ${ }^{12} \mathrm{O}$ quadro apresenta elementos da obra e da personalidade de Warburg articulados de forma sintética. $\mathrm{O}$ artista representou-o com corpo de uma Mênade, lembrando as pesquisas de Warburg sobre a questão do Pathosformel, e a cabeça do próprio Aby Warburg, recriada a partir de um retrato tirado durante sua estadia nos Estados Unidos, em visita aos índios Hopi, uma alusão ao seu conceito de polaridade e, talvez também aos seus anos de loucura, dos quais emergiu escrevendo um texto sobre essa experiência. Porém as afinidades entre a pintura e a obra de Warburg não param por aí. No quadro, assim como em muitos outros que o artista pintou posteriormente, vemos sua tentativa de adotar um método de trabalho correspondente ao utilizado por Warburg em seu projeto mnemosyne. O processo de recolhimento de imagens significativas relacionadas a um determinado tema, e sua articulação em uma imagem síntese, assemelha-se às análises que Warburg fazia do processo de construção das imagens coletivas. ${ }^{13}$ As imagens criadas por Ron Kitaj, assim como as estudadas por Aby Warburg, revelam-se como constelações complexas e multifacetadas, que criam uma rede de significados dentro de uma determinada cultura. ${ }^{14}$ A justaposição de imagens na obra de Ron Kitaj, que a princípio poderia lembrar um procedimento pop de aproveitamento de imagens que já circulam na cultura, revela assim uma outra natureza e vincula-se a uma discussão sobre os processos de formação das imagens na memória.

Os mesmos procedimentos utilizados para compor "Warburg como Mênade", podem ser identificados em seu quadro "O Neo-Cubista" (Fig. 3), pintado entre 1976 e 1987, como uma homenagem a seu amigo David Hockney. Aqui, novamente encontramos uma síntese entre diversas imagens que aludem ao universo do artista Pop. Kitaj pinta Hockney diante de uma piscina, fazendo referencia direta a seu mais famoso quadro da época em que o artista morou na Califórnia. Seu corpo lembra porém um desenho de Benvenuto Cellini criado em 1563 como emblema para a Accademia Del Disegno em Florença que, segundo Doppner, referia-se a uma lembrança comum da época em que os dois artistas estudaram juntos na "Royal Academy"

\footnotetext{
11 Matin Roman Doppner, Bilder als Kommentare R.B. Kitaj und Aby Warburg”, in: Horst Bredekamp, Michael Diers e Charlotte Schoell-Glass (org.), Aby Warburg. Akten des internationalen Symposions Hamburg 1990, Hamburg: Acta humaniora, 1990, p.235-260.

12 Idem.

13 Martin Doppner comenta sobre o assunto: "Na medida em que Kitaj estabelece novas relações entre os símbolos apresentando-os em novos contextos, podemos ver em que medida ele se orienta, metodologicamente, no Atlas de Imagens de Warburg, que demonstrava as transformações das imagens." Idem, p.251.

14 A justaposição de imagens na obra de Ron Kitaj, que a princípio poderia lembrar um procedimento pop de aproveitamento de imagens que já circulam na cultura, revela assim uma outra natureza e vincula-se a uma discussão sobre os processos de formação das imagens na memória coletiva.

${ }^{15}$ Idem, p. 251.
} 
"retrato duplo" que Warhol pintara do artista em 1974. Como afirma Doppner, "O método de Kitaj (...) transforma os métodos tradicionais da Iconologia numa iconologia correspondente a uma estética moderna." 16

A obra mais recente do artista Wesley Duke Lee apresenta algumas semelhanças marcantes com relação à produção de Ron Kitij e com os princípios warburgianos descritos acima. Apesar da historiografia da arte brasileira reconhecer a importância de Wesley para a construção do cenário cultural e artístico da cidade de São Paulo nos anos 60 e 70, ressaltando a importância de suas atitudes no grupo Rex e dos primeiros happenings realizados pelo artista no país, a riqueza e complexidade da maior parte de sua produção, posterior a este período, ainda permanece desconhecida do grande público.

A obra de Wesley Duke Lee tomará novos rumos a partir do final da década de 70, quando o artista, talvez sob o impacto da leitura de Jung, passou a se interessar pelas conexões subterrâneas presentes entre a psicologia individual e a memória coletiva, expressas na cultura através do retorno cíclico de determinados temas e imagens. Nesse período, cresce o interesse de Wesley pela civilização clássica, que surge como matriz fundamental do arquivo visual que constitui a cultura ocidental. Dois painéis realizados pelo artista entre 1962 e 1976 inscrevem-se nesse novo momento de sua produção (Fig.4). Ambos apresentam uma coleção de imagens, afixadas sobre um painel de madeira, que guarda uma semelhança inusitada com os painéis que compõem o Atlas Mnemosyne de Aby Warburg. ${ }^{17}$ Nesses painéis, imagens de diversas épocas e origens distribuem-se em torno de uma obra clássica (no primeiro caso, uma cabeça de medusa, no segundo, um torço retirado do Parthenon de Atenas). Na mesma época, Wesley compõe uma caixaaquivo intitulada "A História da Arte" (Fig.5), onde deposita uma série de gravuras barrocas do século XVIII francês, baseadas em obras renascentistas, demonstrando claramente sua preocupação com a questão da herança das imagens dentro da cultura.

A partir dos anos setenta, cada vez mais, ao lado de imagens criadas pelo próprio artista, acumulam-se as recolhidas pelo mundo e cujo significado depende das ordenações específicas realizadas pelo artista. A série Viagem de Helicóptero à Grécia (1977), faz parte desse mesmo universo temático (Fig.6). $\mathrm{Na}$ série, fragmentos de estatuária grega são representados como heróis que, ainda que mutilados, sobreviveram à batalha da passagem do tempo, conservando toda sua magia e poder. Sobre elas, paira a imagem em xerox (uma técnica inquestionavelmente contemporânea) do modelo do "helicóptero" de Leonardo da Vinci. Através desse xerox, a máquina de Leonardo, que permitiu seu vôo sobre a Grécia e o renascimento da cultura clássica no cinquecento, comunica-se também com o nosso tempo, transportando a memória das formas através dos séculos. ${ }^{18}$ Os trabalhos da série Viagem de Helicóptero à Grécia encenam uma narrativa do percurso das imagens no tempo, considerando-as, à semelhança do Atlas Mnemosyne de Warburg.

Outra série de Wesley que apresenta semelhanças importantes com as teorias de Warburg sobre o funcionamento das imagens é a da Cartografia Anímica, realizada em 1980,

\footnotetext{
16 Idem, p.254.

17 Indagamos certa vez ao artista se ele tinha conhecimento da obra de Aby Warburg, ao que ele espondeu negativamente. Assim, devemos supor que esta semelhança seja fruto de reflexões parecidas a respeito do funcionamento da imagem no contexto da cultura contemporânea. Como dissemos, o pensamento de Wesley foi influenciado pelo conceito de arquétipo de Jung, que por sua vez guarda certas semelhanças com o pensamento de Warburg. Também não podemos descartar um conhecimento de Wesley a respeito da obra de uma artista como Ron Kitaj.

18 Devemos recordar, nesse contexto, que também Wesley construíra, inspirado em Leonardo, um Helicóptero (1969) alguns anos antes, para a realização de suas viagens interiores.
} 
no qual Wesley investiga como o universo da mitologia pessoal se organiza em relação às imagens coletivas (Fig.7). A série transformou-se a seguir em uma coleção de gravuras, organizadas em outra caixa-arquivo. Enquanto mapas, cada uma das imagens da série representa uma possibilidade de organização da informação visual que nos rodeia em uma configuração particular e individual. Ainda que as imagens sejam coletivas, sua composição no interior do sujeito é única, resultando em mapas afetivos da alma. Os novos meios de multiplicação da imagem (jornais, revistas televisão, etc.), potencializam este jogo ao infinito, rompendo fronteiras impostas anteriormente pela própria cultura. Encontramos aqui o tom otimista de Wesley com relação às potencialidades da cultura contemporânea. A liberdade de circulação através de tantos universos é vista como um privilégio inigualável do homem de hoje.

Uma das últimas séries criadas por Wesley: Os Trabalhos de Eros funciona, num certo sentido, como uma síntese de inúmeras questões levantadas pelo artista ao longo de sua carreira. A busca pela origem, perseguida no contexto de sua própria psicologia individual nos anos sessenta na série Ligas, retorna aqui em um contexto universal e ganha uma face na figura do pequeno criador Eros. O pequeno herói é apresentado como fonte de todo poder criativo e fonte primeira da criação artística. Significativamente, a série abre com a figura da Memória (Fig.8), da qual, segundo o próprio artista, "dependemos para dar continuidade à civilização". Assim, as imagens coletivas que tanto interessaram Wesley na década anterior, apresentam-se como a matéria prima para a criação na arte, impulsionada pela relação erótica que o homem estabelece com o mundo. Toda a série é realizada através do uso de computadores e da técnica de scannaprint, o que atribui uma marcante contemporaneidade às questões discutidas no trabalho.

Certa vez, ao encontrar Wesley, perguntei se ele conhecia a obra de Aby Warburg, tendo recebido uma resposta negativa. Certamente ele conhece bem a produção de Ron Kitaj, que era discutida nos círculos intelectuais e artísticos dos anos 70 em São Paulo. De qualquer maneira, não há como negar uma semelhança marcante entre a forma de pensar os processos de formação da memória coletiva através das imagens nos três autores. A proximidade entre as obras de Kitaj, Wesley e Warburg aponta para a contemporaneidade do pensamento e dos métodos de Aby Warburg.

\section{Legendas texto Arquivos da Memória: Claudia Valladão de Mattos}

Fig. 1 - Aby Warburg “Atlas Mnemosyne”, fotografias sobre cartolina preta, prancha 45, 1924-29, Instituto Warburg, Londres.

Fig. 2 - Ron Kitaij, "Warburg como Mênade", Óleo e colagem sobre tela, 1962, Kunstmuseum Dusseldorf.

Fig. 3 - Ron Kitaij, “O Neo-cubista”, 70 x 52 cm, Óleo sobre tela, 1976-87, Coleção Saatchi, Londres.

Fig. 4 - Wesley Duke Lee, "Fragmento amarelo III, as sombra ações"

Colagem, desenhos, gravuras, estampas, xerox e têmpera sobre papel, $123 \times 123 \mathrm{~cm}$, 1962/76, Coleção Luisa Strina, São Paulo. 
Fig. 5 - Wesley Duke Lee, "História da arte", 10 x 38 x 52 cm, sem data, coleção do artista.

Fig. 6 - Wesley Duke Lee, "Sobrevoando os mysterios de Elêusis, Kore pisando no mundo de Apolo", lápis de cor, colagem e xerox s/ papel, 76,5 x 56,5 cm, 1977, coleção Augusto Lívio Malzoni, São Paulo.

Fig. 7 - Wesley Duke Lee, “Cartografia anímica n. ${ }^{\circ}$ 794”, frotagem, carimbo, lápis e sumi-êe sobre papel, 56 x 76 cm, 1980, coleção Galeria Luisa Strina, São Paulo.

Fig. 8 - Wesley Duke Lee, "Os trabalhos de Eros - A memória", pintura digital acrílica, pastel e lápis cera s/tela, 130 x 147 cm, 1991, Coleção Kim Esteve, São Paulo. 